Revista lus et Praxis, Año 24, No 3, 2018, pp. 421 - 452

ISSN 0717 - 2877

Universidad de Talca - Facultad de Ciencias Jurídicas y Sociales

El comiso penal en la legislación estadounidense como

horizonte comparativo frente al Proyecto de Nuevo Código Penal

Cristóbal Hasbún L.

Trabajo recibido el 29 de marzo de 2017 y aprobado el 28 de septiembre de 2018

\title{
El comiso penal en la legislación estadounidense como horizonte comparativo frente al Proyecto de Nuevo Código Penal
}

\author{
CRIMINAL CONFISCATION IN AMERICAN LEGISLATION AS A COMPARATIVE VIEW IN \\ contrast With the Project for a New Criminal Code
}

CRistóbal Hasbún L.*

RESUMEN

El presente trabajo tiene por finalidad cotejar la regulación del comiso en las disposiciones penales vigentes y en lo dispuesto por el Proyecto de Nuevo Código Penal (2014), frente a la normativa y recepción jurisprudencial estadounidense sobre dicha materia. Este ejercicio ofrece reflexiones e ideas para un futuro sistema de comiso en Chile, esperando contribuir a esclarecer los principales problemas que presenta una legislación sobre comiso y a qué criterios se debe atender para darles una correcta respuesta.

\section{ABSTRACT}

This article aims to compare the regulation on confiscation in the existing law and in the rules of the Project for a New Criminal Code (2014) in contrast with the American regulation and case law on that matter. This exercise presents reflections and ideas for future confiscation legislation in Chile, hoping to contribute to make clear the main problems that confiscation laws have and which are the criteria that should be considered to solve them.

Palabras Clave

Comiso, criminalidad organizada, comiso de ganancias

KEY WORDS

Confiscation, organized crime, confiscation of proceeds

\section{Introducción}

Cuando hablamos del comiso penal debemos tener presente que nos referimos a una potestad del Estado de privar legítimamente de bienes a personas jurídicas o naturales cuando éstos son fruto de la comisión de un delito. La necesidad de desarrollar dicho sistema de reglas encuentra su justificación en dos razones. La primera es una de justicia y, la segunda, criminológica. La razón de justicia tras una correcta legislación de comiso dice relación con

* Licenciado en Ciencias Jurídicas, Universidad Adolfo Ibáñez. Magíster en Derecho Penal, Universidad de Chile. Investigador del Centro de Estudios Penales, Universidad Mayor. Candidato a Dr. jur en derecho penal, Goethe- Universität, Frankfurt am Main. Correo: hasbuncristobal@gmail.com. 
dar cumplimiento al antiguo principio jurídico: nadie puede enriquecerse de su propio dolo. El comiso es una materialización de ello. A su vez, la justicia penal patrimonial no se satisface exclusivamente con la irrogación de la pena (cuestión que puede ser contingente a los ojos del ofendido), sino que con la restauración del estado de cosas antes de la comisión del ilícito. La víctima del delito ciertamente considera justo que su patrimonio se restituya. Esa es otra función del comiso. Por otro lado, y esto se refiere a la segunda razón, se ha observado en las últimas décadas una creciente sofisticación en la ejecución de delitos por parte de bandas organizadas, lo que ha llevado a que países de nuestro horizonte de derecho comparado reconfiguren sus leyes de comiso para combatirlo. Del mismo modo, el reciente crecimiento económico en Chile y su correlativa acumulación de capitales, ha presentado la necesidad de desarrollar esta herramienta jurídica en aras de enfrentar la incipiente complejización en la organización del crimen, herramienta que permite privar al hechor de aquello que constituye el objetivo de su delito, esto es, las ganancias.

La figura mentada se encuentra en nuestra legislación ya desde la época del legislador decimonónico' ${ }^{2}$ Ésta cumplía con la misión de privar de los bienes al hechor en circunstancias en que éstos fuesen obtenidos como ganancias provenientes de un delito. La escueta formulación vigente resulta perfectamente adecuada a la forma de criminalidad de aquel siglo, donde la organización delictual no presentaba el nivel de elaboración que presenta hoy en día. Del mismo modo que las organizaciones productivas han ido perfeccionando su forma de trabajo empresas, fábricas, industrias las organizaciones "productivas" ilícitas lo han ido perfeccionando también².

\footnotetext{
${ }^{1}$ El comiso se encuentra establecido en el artículo 31 del Código Penal chileno como una pena pecuniaria accesoria. Éste fue tomado del artículo 59 del Código Penal español de 1848 (1850) con ínfimas variaciones, el que a su vez dio pie a lo dispuesto en tal materia, de modo bastante similar, en el Código de 1944 (1973). El artículo 31 del Código Penal chileno, de 1875, expresa: "Toda pena que se imponga por un crimen o simple delito, Ileva consigo la pérdida de los efectos que de él provengan y de los instrumentos con que se ejecutó, a menos que pertenezcan a un tercero no responsable del crimen o simple delito". El artículo 59 del Código Penal español de 1848 (1850) disponía: "Toda pena que se imponga por un delito Ileva consigo la pérdida de los efectos que de él provengan y de los instrumentos con que se ejecute (...)". Por otra parte, el artículo 63 del Código Penal de 1870 expresaba: "Toda pena que se impusiere por un delito llevará consigo la pérdida de los efectos que de él proviniesen y de los instrumentos con que se hubiere ejecutado". Finalmente, el artículo 48 del Código Penal español de 1944 (1973) sostenía que: "Toda pena que se impusiere por un delito llevará consigo la pérdida de los efectos que de él provinieren y de los instrumentos con que se hubiere ejecutado (...)".

${ }^{2}$ Lo anterior resulta observable, entre otros criterios, atendiendo a la cuantía de los montos provenientes de los delitos. Así, por ejemplo, entre 2007 y 2015 se dictaron en Chile 81 condenas por lavado de activos. El 88\% de las condenas tiene como delito base uno de drogas, 14,8\% se distribuye en varios delitos de corrupción y 7,4\% en la obtención fraudulenta de créditos. La cuantía del comiso en los casos de sentencias condenatorias por lavado de activos sentenciados por Tribunales de Justicia
} 
La expansión del fenómeno criminológico descrito ha encontrado recepción en el derecho comparado. Legislaciones tales como la estadounidense, alemana, suiza, española y británica, han realizado modificaciones a sus antiguos sistemas de comiso o han elaborado nuevas normativas ${ }^{3}$. La disparidad que existe entre el cúmulo de reglas nacionales de 1875 respecto la materia en contraposición al derecho comparado ha sido advertida por la comisión para un Proyecto de Nuevo Código Penal (PNCP) ${ }^{4}$. Pero pese a que su articulado es en general asertivo, no es suficiente. Ello vuelve necesaria la revisión comparada de la legislación de uno de los países cuyo sistema de comiso penal resulta ostensiblemente más desarrollado, como es el caso de EE.UU., con la finalidad de cotejarlo con la legislación nacional vigente y lo dispuesto en el PNCP.

La idea rectora del presente trabajo es que una nueva reglamentación del comiso debe ser expansiva y especializada. Que sea expansiva quiere decir que se debe hacer cargo del fenómeno del comiso como uno que tiene elementos de derecho administrativo, civil y penal. Lo anterior descansa en la idea de que la comprensión exclusiva del comiso como uno criminal es insuficiente para captar la complejidad de las diversas formas de enriquecimiento ilícito. Que sea especializada quiere decir que debe ser una legislación que, cubriendo las tres áreas mentadas, debe incorporar la mayor cantidad de hipótesis de comiso posibles. Esto significa que no sólo debe permitirse la recuperación de ganancias ilícitas fruto de la comisión del hecho punible, sino también el ahorro de costos mediante hechos ilegales, el comiso por valor equivalente o uno sin necesidad de previa culpabilidad.

entre 2007 y 2015 asciende a \$6.614.- millones de pesos (\$ 9.4 millones de dólares). La cifra de dinero recuperado por el fisco ciertamente podría ser mayor, considerando que entre los años 2007 y 2011 hubo 42 condenas por lavado de activos, de las cuales sólo en 19 se hizo operativo el comiso. Unidad de Anállsis Financiero (2016), pp. 19-25. Por otro lado, en el "El caso Riggs" se condenó a presidio a seis funcionarios por el delito de malversación de caudales públicos. Se ordenó el comiso de 24 inmuebles, 3 vehículos, 7 instrumentos bancarios, \$4.894.638,1 USD y \$124.566.242 pesos pertenecientes a Augusto Pinochet Ugarte o a alguna de sus sociedades, en Corte de Apelaciones de Santiago, rol № 1649-2004, de 21 de junio de 2017, considerando decimoprimero. En el caso La Polar, donde un conjunto de directores y ejecutivos de una empresa dedicada al retail y acciones bursátiles cometieron delitos de estafa, infracción a la ley de mercado de valores, falseamiento de estados contables y lavado de activos, lo que llevó a que a tres de los condenados les fueran decomisados la totalidad de \$676.537.332. En Tribunal Oral en lo Penal de Santiago, RIT Nº 6930-11, de 18 de diciembre de 2015, considerando quinto.

3 Alemania añadió una cláusula de aplicación general de comiso el año 1975. Estados Unidos reformó su sistema de comiso el 2000, Suiza y España complementaron su normativa en 1995, Austria en 1996 e Inglaterra y Escocia en 2001.

${ }^{4}$ Refiriéndonos a la comisión llamada por el Presidente Piñera el año 2014 e integrada por los profesores Juan Domingo Acosta, Jorge Bofill, Héctor Hernández, Francisco Maldonado, Juan Pablo Cox, Alex van Weezel y Antonio Bascuñán. 
Las razones por las cuales se ha escogido la legislación estadounidense como horizonte comparativo radican, en primer lugar, en que la normativa de comiso de dicho país descansa en la idea de que el comiso penal es la piedra angular sobre la cual gira la organización de los otros sistemas de comiso. Se trata de una forma mínima necesaria que se ve complementada con uno civil y administrativo. Atendiendo a que nuestra legislación requiere una reforma que cubra estas tres áreas, es necesario comenzar por la penal. En segundo lugar, porque dentro del derecho comparado es el sistema que cubre la mayor cantidad de hipótesis, constituyéndose como un sistema de reglas especializado (se refiere a las reglas de recuperación de bienes de propietarios inocentes, ofrece una audiencia especial para el comiso, dispone la posibilidad de que éste sea apelado, entre otras). Finalmente, porque el comiso penal en el país mentado es uno de los tres pilares de un sistema complejo que, al operar en conjunto con su versión administrativa y civil, ha dado luces de ser uno de los más efectivos ${ }^{5}$.

Existe conciencia por parte del autor que la tradición jurídica angloamericana es distinta a la latinoamericana en algunos pasajes, pero los criterios rectores de justicia tienden a asimilarse. Se ha optado metodológicamente por tener como referencia la tradición estadounidense sobre este tema porque, al tratarse de cuestiones relativas a garantías constitucionales y debido proceso, éstos tienden a ser asimilables a nuestra tradición constitucional-penal bajo principios fundamentales como el derecho a defensa, la presunción de inocencia y el principio de proporcionalidad ${ }^{6}$. El presente trabajo no tiene por objetivo importar desconsideradamente conceptos, reglas o instituciones de Estados Unidos, sino ofrecer un punto de parangón cuyos contenidos funjan como criterios orientadores para encontrar mejores soluciones y conocer la experiencia comparada a la hora de discutir sobre este tema.

El presente trabajo está comprendido por cuatro partes. La primera de ellas presenta la escaza discusión dogmática nacional respecto a la interpretación del comiso dispuesto en el artículo 31 del Código Penal. Esta parte cumple con demostrar que el desarrollo de dicha herramienta en nuestra legislación es deficiente. La segunda de ellas, explica el desarrollo normativo y jurisprudencial de dicho sistema en Estados Unidos. Este punto tiene por finalidad exponer la

\footnotetext{
${ }^{5}$ Se trata del sistema con una de las mayores cifras de recuperación de activos. La última cifra indica que desde mediados del 2000 hasta el 2013, la propiedad decomisada anualmente en EE.UU. aumentó de \$ 500 US millones a \$1.5US billones, CASSELLA (2013), p. xxxiii.

${ }^{6}$ Los principios constitucionales-penales estadounidenses, así como su sistema de comiso, han demostrado ser un horizonte de referencia para legislaciones occidentales, permitiendo una correcta aproximación metodológica a ellos. Los sistemas de comiso estadounidense y europeos, con independencia de su tradición anglosajona o continental, han evolucionado las últimas décadas teniendo a la vista estudios comparativos recíprocos, Ruı et al. (2015), p. 302.
} 
técnica legislativa en esa nación y su nivel de especialización. La tercera parte exhibe un análisis comparado entre aquel sistema y lo propuesto por el PNCP revisando elementos tales como la forma en que se protege a propietarios que son terceros inocentes, el problema del comiso en el ahorro de costos, la cuestión de la legitimidad del pago de abogados particulares en el proceso de comiso y el destino de los bienes decomisados. A pesar de que el PNCP se trata de un intento contundente de propuesta de lege ferenda, se expondrán sus déficits y carencias en lo relativo a la necesidad de su expansión y especialidad. Finalmente, en el cuarto punto el trabajo ofrece conclusiones.

El autor quisiera prevenir que durante extensos pasajes este trabajo ofrece una descripción técnica del procedimiento de comiso en una legislación más compleja. La necesidad de incluir aquellos áridos recorridos radica en que en la actualidad no existen manuales respecto comiso en español sobre los cuales trabajar. Lo anterior no quiere decir que a futuro no se pueda construir una dogmática penal sobre este tema, por el contrario, resulta necesario que el comiso sea correctamente integrado al análisis dogmático penal. Pero teniendo a la vista que actualmente resulta de primera necesidad la discusión y promulgación de un nuevo Código Penal, el primer paso en esta materia es exponer el funcionamiento básico de sus reglas.

\section{Artículo 31 del Código Penal}

El único trabajo del que tenemos noticia publicado en la dogmática penal nacional dedicado exclusivamente al comiso penal, dispuesto en el artículo 31 del dicho Código, corresponde a Ananías. Éste se pregunta por la definición expansiva o restrictiva de la locución efectos, intentando elaborar una clasificación de ésta ${ }^{7}$. Siguiendo su constructo, la expresión efectos del artículo 31 ofrece cinco clasificaciones ${ }^{8}$ :

En primer lugar se encuentran quienes como Labatut entienden por ellos "los objetos o el dinero de que se apropió el delincuente" ${ }^{\prime \prime}$, planteando como sinonimia los efectos del delito con el objeto material del hecho. Lo anterior llevaría a difuminar la delimitación entre producto sceleris y sceleris quoestia.

\footnotetext{
${ }^{7}$ Artículo $31 \mathrm{CP}$ "Toda pena que se imponga por un crimen o simple delito, lleva consigo la pérdida de los efectos que de él provengan y de los instrumentos con que se ejecutó, a menos que pertenezcan a un tercero no responsable del crimen o simple delito".

${ }^{8}$ Ananías (2014), pp. 183-186.

${ }^{9}$ Labatut (1979), p. 293.
} 
En segundo lugar se encuentran Guzmán ${ }^{10}$, Hernández $z^{11}$ y Suárez ${ }^{12}$, quienes entienden que producto sceleris son sólo aquellas cosas que tienen su origen en el delito o que le deben su composición actual, excluyendo, luego, el objeto del delito (objetum sceleris). Esta postura permite una distinción entre el dinero y los efectos del delito, pese a que ésta no existe en el ordenamiento chileno.

En tercer lugar se encuentran Etcheberry, Cury, Garrido y Politoff, quienes sostienen que es extensible el ámbito de aplicación de los producto sceleris más allá del objeto cuyo origen material o estructura actual es reconducible al hecho punible. Lo anterior se basa en los conceptos que enuncian: "[l]os efectos del delito (...) son los objetos materiales sobre los cuales haya recaído la acción delictiva o que sean producto de ella"13. Ello se condice con la crítica que los autores hacen a determinados tipos delictivos especiales $(v$. gr. delitos de cohecho y tráfico ilícito de estupefacientes) donde consideran que la especificación del legislador relativa a que los objetos de estos delitos deben ser decomisados es un error legislativo ${ }^{14}$.

En cuarto lugar se encuentra la tesis de Novoa, quien sostiene que "deben considerarse efectos provenientes del delito las cosas materiales que han resultado del hecho punible (moneda falsa, armas prohibidas que se han fabricado, dinero ganado en juegos de azar, etc. $)^{15}$. Esta tesis resulta extensiva pero más restrictiva que la anterior, toda vez que incluye dentro de los efectos sólo las cosas que tienen su origen en el delito y aquellas que son del autor al momento de su comisión.

En quinto lugar nos encontramos con la posición adoptada por la Corte Suprema el año 2012, la cual es aún más extensiva, pues incluye dentro de los efectos a las ganancias. La Corte Suprema expresa: Que la modalidad del régimen de comiso que estableció la ley especial $N^{\circ} 19.366$ con respecto al general consagrado en el Código Penal, es la designación en él de las drogas tóxicas, porque todos los demás bienes allí consignados constituyen precisamente los instrumentos o efectos del delito o las ganancias que de él derivan, de modo que no era necesaria su mención expresa, pues resultarían siempre decomisables de acuerdo a las reglas generales del estatuto punitivo.

\footnotetext{
${ }^{10}$ GuZMÁN (2009), p. 336.

${ }^{11}$ Couso et al. (2011), p. 483.

${ }^{12}$ Couso et al. (2011), pp. 497 y 502.

13 EtCheberry (1998), p. 167; Cury (2005), p. 751; Garrido (2001), p. 300; Politoff et al. (2002), p. 268.

${ }^{14}$ Novoa (2005), p. 344; Cury (2005), p. 751; EtCheberry (1998), p. 167.

15 NovoA (2005), p. 344.
} 
El COMISO PENAL EN LA LEGISLACIÓN ESTADOUNIDENSE COMO horizonte comparativo frente al Proyecto de Nuevo Código Penal

Y continúa sosteniendo: Que, la sentencia impugnada, al excluir del comiso ciertos bienes por la exclusiva consideración que esa sanción resulta originaria en la Ley $N^{\circ}$ 19.366, importa un error de derecho por errada interpretación del artículo 27 de la Ley No 19.366, unida a la falta de aplicación de la regla general del artículo 31 del Código Penal que en términos perentorios prescribe que toda pena que se imponga por un crimen o un simple delito, Ileva consigo la pérdida de los efectos que de él provengan, y de los instrumentos con que se ejecutó, a menos que pertenezcan a un tercero no responsable del crimen o simple delito, cuyo no ha sido el caso, norma que a la data de los hechos estaba vigente por lo que su aplicación al caso de marras es obligatoria ${ }^{16}$.

El considerando anterior da cuenta que la Corte entiende que el artículo 31 incorpora dentro de su ámbito de aplicación los efectos y las utilidades que hubiere generado el delito, con independencia de su naturaleza jurídica o las transformaciones que éstas hubiesen sufrido ${ }^{17}$. En este sentido, el así llamado comiso de ganancias se encontraría incluido en el campo semántico de la palabra efectos. Lo anterior no es trivial, dado que permite a la interpretación del adjudicador ejecutar el comiso en un sentido extensivo, incluyendo sea las ganancias producidas con dinero ilícito en un proceso de reinversión o las ganancias que provienen de un ahorro o devolución ilegal por parte de una persona natural o jurídica ( $v$. gr. mediante la omisión de declaraciones tributarias a las cuales la ley obliga bajo sanción penal). Sí resulta trivial, en cambio, si se tiene a la vista la definición que el PNCP da sobre comiso $^{18}$ (la cual elimina la necesidad del problema clasificatorio).

La definición anterior disuelve algunos problemas de delimitación de dicho concepto. Actualmente nuestra legislación no contiene una descripción achurada de qué significa el comiso, lo que en principio no delimita su rango de operatividad. El derecho estadounidense no define el comiso pero sí su rango de acción: la propiedad que una persona obtiene o retiene como una consecuencia del delito ${ }^{19}$. Siendo visto como positivo el hecho que una definición amplia no restrinja per se su rango de acción, sí se debe hacer notar que resulta necesaria una elaboración doctrinal (no sólo desde el derecho penal sino también desde el derecho privado y administrativo sancionatorio) con la finalidad de determinar la naturaleza jurídica de la institución mentada. Esto es, un estudio que

\footnotetext{
${ }^{16}$ Corte Suprema, rol No 7480-10, de 25 de junio de 2012.

17 AnANías (2014), p. 189.

${ }^{18}$ Artículo 126 PNCP "Por el comiso se priva a una persona de la propiedad de bienes determinados y se la transfiere al fisco".

${ }^{19}$ Cassella (2013), pp. 900-901. Se previene que la locución obtiene debe ser considerada en un sentido laxo, dado a que no es un modo de adquirir el dominio.
} 
configure una respuesta jurídica sistematizada respecto si el comiso se trata de una acción exclusivamente penal; penal y administrativa sancionatoria; penal, administrativa y civil o una acción como resultado de un enriquecimiento injusto como consecuencia de una infracción a derecho público general.

La necesidad de clarificar la naturaleza jurídica de la herramienta en cuestión se ve reforzada por el hecho de existir, aunque algo desapercibido, un comiso administrativo en Chile $^{20}$. Lo anterior reviste particular interés atendiendo a que, por un lado, no existe mayor pronunciamiento jurisprudencial sobre éste, y por otro, considerando que la legislación estadounidense contempla su figura de comiso administrativo como la más eficiente. A pesar de ello, nuestro sistema sólo se encuentra enunciado en un número reducido de leyes especiales, distando con creces de la elaboración normativa que expresa aquel ${ }^{21}$.

La forma decimonónica en que dicha herramienta está configurada es expresiva de una forma de delincuencia clásica, ahí donde se pretende que el comiso permita privar al hechor del instrumento con que cometió el delito (habitualmente armas) y las ganancias (comúnmente el producto del daño al patrimonio). Pero su formulación no permite solucionar con relativa nitidez delitos más complejos, como estafas piramidales donde con las ganancias ilícitas se capitaliza una empresa (¿cuál es la extensión de un comiso legítimo?), donde una malversación de fondos públicos pasa como parte de la sucesión testamentaria a los herederos producto de la muerte del comisor (¿bajo qué reglas de comiso se puede privar a la sucesión de dicho enriquecimiento ilegal?) o en el caso de que existan fundadas sospechas de que un bien presuntamente

\footnotetext{
${ }^{20}$ El cual se encuentra dispuesto en diversas reglas de derecho administrativo sancionatorio; tales como la Ley N 18.892 de 1989 de pesca y acuicultura que en los artículos 114, 115 y 116 sanciona con comiso la infracción a las reglas de extracción de especies hidrobiológicas, la Ley № 18.410 de 1999 que crea la Superintendencia de Electricidad y Combustible, que en sus artículos 16 y $16 \mathrm{~A}$ establece el comiso como sanción, la Ley № 20.283 de 2008 sobre recuperación del bosque nativo y fomento forestal, que en sus artículos 51 y 52 establece que toda infracción a las reglas de corta de bosques tendrá aparejada el comiso de las especies, el D.F.L. № 213 de aduanas que establece en sus artículos 136, 137 y 151 las reglas sobre mercancías presuntamente de contrabando, ilícitas o abandonadas, donde se incluye el comiso de éstas, la Ley № 19.419 de 1995 que regula las actividades relacionadas con el tabaco donde en su artículo 16 se establecen multas y comiso de especies producidas, comercializadas o tratadas de modo contrario a la ley, así como la Ley № 11.564 de 1954 sobre el beneficio habitual de animales vacunos, de la cual el artículo $4^{\circ}$ estipula que caerán en comiso las ventas de especies producidas con infracción a dicha ley. Sin perjuicio de ello, la búsqueda de jurisprudencia arroja una casi nula aplicación del comiso. Ello lleva a pensar que el comiso administrativo existe en nuestro ordenamiento, pero sólo en la letra de la ley. Lo anterior puede explicarse por dos motivos. El primero, por la dificultad posterior relativa a qué hacer con las especies decomisadas (especies hidrobiológicas, árboles nativos, animales, etc.) y, la segunda, por la exigua cultura que nuestro sistema jurídico presenta en estas materias.
}

${ }^{21}$ Cassella (2003), pp. 314-360. 
abandonado estaba envuelto en un hecho delictivo (¿bajo qué reglas se puede decomisar un automóvil o un barco abandonado, presuntamente utilizados para cometer delitos?). El inmenso número de hipótesis sobrepasa la capacidad de rendimiento de las disposiciones vigentes.

Es relevante para los efectos de dimensionar el déficit de reglas que nuestra legislación exhibe en esta materia tener presente que resulta necesario que dicha normativa dé cuenta de que el comiso es una cuestión de derecho extensivo. Esto quiere decir que no se trata exclusivamente de una prerrogativa criminal, sino también administrativa y de derecho privado ${ }^{22}$. La configuración administrativa debe permitir una recuperación eficiente de bienes sin necesidad, en principio, de un proceso judicial. La civil debe facultar a la judicatura para desarrollar un procedimiento sobre los bienes presuntamente ilícitos en aquellos casos en que se pueda prescindir de la culpabilidad penal del hechor. Se trata, a su vez, de una forma más expedita de recuperación de ganancias ilícitas sin la amplia batería de garantías constitucionales del proceso penal, pero con mayor protección del sujeto eventualmente decomisado que en el procedimiento de comiso administrativo.

La exposición de reglas desperdigadas de comiso administrativo da cuenta de que existe la necesidad y voluntad legislativa de estipularlo. Pero éste requiere de reglas que tiendan a la especialización. Esto es: disposiciones que expresen qué bienes pueden decomisarse (¿se incluyen, por ejemplo, inmuebles?) y cuáles son algunas limitaciones a este proceso, atendiendo, por ejemplo, a la cuantía del bien o a la naturaleza del delito en que supuestamente se vio involucrado. El criterio de especialización exige, a su vez, que el procedimiento de comiso administrativo se encuentre debidamente reglado. Dichas disposiciones deben estar estipuladas bajo una racionalidad sistémica que le permita al juez hacerlas operativas en consonancia con las reglas de comiso penal. Eso requiere que, al momento de revisar la elaboración de dicha normativa, se ejecute dicha empresa con un horizonte común respecto lo que el comiso significa y con reglas procedimentales conjuntas al momento de su ejecución. Es recomendable que las reglas en las distintas sedes de comiso, como lo demuestra el derecho comparado estadounidense, tiendan a la unificación.

\footnotetext{
${ }^{22}$ El derecho de la Comunidad Europea también ha entendido que el comiso es una cuestión de derecho extensivo que sobrepasa una mera naturaleza penal. Reconociendo que tiene una importante dimensión criminal, ésta no agota las posibilidades, Ruı et al. (2015), p. 245. Dicha extensión ha presentado el problema de que este tema se encuentra tratado a menudo de manera dividida y fragmentada en distintos cuerpos normativos. Ello se debe, probablemente, a que no ha existido una correcta reflexión sobre la justificación y el sentido del comiso, sino que se ha legislado de manera sobrepuesta en distintas áreas del derecho, Boucht (2017), p. 95.
} 


\section{El comiso en Estados Unidos}

\subsection{Historia y tripartición}

El comiso estadounidense se divide en tres categorías: el administrativo, civil y penal. Cada cual tiene una justificación distinta y procedimientos diferenciados. En términos históricos, la institución se remonta al comiso civil, el cual importa una acción sobre la cosa decomisable, por tanto se denomina acción in rem, al igual que el comiso administrativo. Lo anterior es una ficción legal que afirma que la cosa es culpable de un hecho ilícito. El comiso penal, en cambio, es una acción que recae sobre la persona (in personam), por lo que se requiere de un juicio de culpabilidad previo. Una vez establecida la participación penal de un sujeto en determinado delito, entonces se procede al decomiso de bienes envueltos en la acción.

El comiso penal evolucionó en la legislación estadounidense a uno extensivo, donde el Estado tiene la potestad de decomisar no sólo los instrumentos del delito sino sus efectos y en general cualquier bien que se haya visto involucrado en el ilícito, sin importar que éste, en principio, sea propiedad de un tercero ${ }^{23}$. La ley dispone una acción restitutoria para la recuperación de éste por parte del propietario inocente (inocent owner).

Existe en la legislación estadounidense un tercer tipo de comiso el cual surgió de la práctica de instituciones como la $\mathrm{LEA}^{24}$, el $\mathrm{DEA}^{25}$ en casos de drogas, el $\mathrm{FBI}$ en materia de fraudes o el $\mathrm{ATF}^{26}$ en cuestiones de tráfico de armas, donde éstas tienen las facultades de incautar bienes en el curso de una investigación sobre los cuales existe sospecha fundada de que formen parte de un ilícito. Este es el comiso administrativo. En general este sistema de comiso requiere de una autorización judicial previa. Una vez que él o los bienes son incautados ${ }^{27}$, la agencia debe informar a todas las personas potencialmente interesadas en los objetos de que éstos se encuentran en tal calidad y que, de no mediar un reclamo dentro de plazo, entonces los bienes se darán por decomisados.

El comiso es una herramienta que comenzó a tomar un rol protagónico en 1970 cuando el Congreso de EE.UU. promulgó el protocolo contra la prevención

${ }^{23}$ CAssella (2013), pp. 13-14.

${ }^{24}$ Law enforcement agencies o Agencias para el Cumplimiento de la Ley, en adelante ACL.

${ }^{25}$ Drug Enforcement Administration o Agencia de Ley de Drogas.

${ }^{26}$ Bureau of Alcohol, Tobacco and Firearms o Departamento de Alcohol, Tabaco y Armas.

${ }^{27}$ Se entiende por incautación (seizure) el acto de algún funcionario del Estado en que se apodera de determinados bienes sobre los cuales existen fundadas sospechas de ser parte de un ilícito. Se encontrarán decomisados (forfeited) una vez que el dominio ha pasado del antiguo propietario al fisCo. WORRAL (2004), p. 222. 
del abuso de drogas (comprehensive drug abuse prevention and control act), el cual autorizaba especialmente un comiso civil sobre el material decomisado (estupefacientes, material para producirlos, equipos de transportación, etc.). En 1986 se promulgó el protocolo de anti-abuso de drogas (anti drug-abuse act), en el cual existía la permisión para la policía de decomisar bienes en un monto equivalente al de aquellos utilizados para cometer el delito, pero ya desaparecidos. En los años '90 el comiso volvió a retomar su relevancia al promulgarse el estatuto más extensivo de comiso en EE.UU., correspondiente al 18 U.S.C. $\S 981(\mathrm{a})(1)(\mathrm{C})^{28}$. Este autoriza el comiso de ganancias sobre más de 200 delitos, tanto federales como estatales, incluyendo fraudes, sobornos, malversación de caudales públicos, robo; así como también homicidios, apuestas ilegales, tráfico de drogas y lavado de dinero ${ }^{29}$. El año 2000, luego de la revisión de dicha normativa en su operatividad durante algunas décadas, se promulgó el más significativo estatuto de reforma sobre la ley de comiso civil, denominado Ley de Reforma del Comiso Civil, en siglas Cafra (civil asset forfeiture reform act). La pregunta relativa a la idoneidad de dicho estatuto de reforma y una eventual extensión a los comisos administrativos y penales sigue vigente.

Con posterioridad al año 2000, la mentada herramienta ha sido sujeto de revisión por parte de los comentaristas estadounidenses, elaborando una crítica a la legislación desde diversas perspectivas. En la actualidad, se ha considerado que merecen una revisión los siguientes aspectos: (1) se ha puesto en duda la idoneidad de que la ley permita que el dinero decomisado vaya a las $A C L$ en la forma que se ha denominado compartir equitativo (equitable sharing). Éste consiste en una disposición legislativa que establece que un porcentaje mayoritario del dinero decomisado irá a las arcas del Estado y lo restante pasará a formar parte del patrimonio de la ACL. Existen comentaristas que sostienen que ello puede constituir un incentivo perverso para la policía ${ }^{30}$, (2) la situación en que queda el propietario inocente de un bien eventualmente sujeto a comiso por actos de terceros o "del mismo bien", bajo la pregunta de si se encuentra

\footnotetext{
${ }^{28}$ Una minuciosa descripción del desarrollo de los sistemas de comiso para combatir la criminalidad organizada en el derecho internacional se encuentra en ZAGARIS et al. (1991), pp. 445-530.

${ }^{29}$ Cassella (2013), p. 28.

${ }^{30}$ AnN-Yu Chi (2003), pp. 1645-1648; Daley (2004), pp. 4-5; GibSOn (2011), pp. 577 y 591; Godfrey (2000), pp. 1723-1724; GORDON (1998), p. 197; HunTER (2013), p. 438.
} 
amparado por la cláusula de debido proceso de la V Enmienda ${ }^{31-32}$, (3) la pregunta con respecto a si el sujeto víctima del comiso tiene o no derecho a valerse de su dinero para pagar defensa privada o se encuentra obligado a recurrir a la defensoría pública, discusión relativa a la interpretación de la VI Enmienda ${ }^{33-34}$, (4) la cuestión de un eventual atentado al debido proceso por infracción al bis in ídem (double jeopardy) ${ }^{35}$ cuando nos encontramos ante procesos de comiso paralelos y (5) la pregunta acerca de sobre quién recae la carga de la prueba ${ }^{36}$.

\footnotetext{
${ }^{31}$ Enmienda V: "Nadie estará obligado a responder de un delito castigado con la pena capital o con otra infamante si un gran jurado no lo denuncia o acusa, a excepción de los casos que se presenten en las fuerzas de mar o tierra o en la milicia nacional cuando se encuentre en servicio efectivo en tiempo de guerra o peligro público; tampoco se pondrá a persona alguna dos veces en peligro de perder la vida o algún miembro con motivo del mismo delito; ni se le forzará a declarar contra sí misma en ningún juicio criminal; ni se le privará de la vida, la libertad o la propiedad sin el debido proceso legal, ni se ocupará su propiedad privada para uso público sin una debida indemnización".
}

32 Cassella (2001), pp. 110-112; Cassella (2004), pp. 322-326; Johnson (2002), pp. 1054-1057; McCaW (2010), p. 202; SKOrUP (2013), pp. 429-431; WiLSON (1991), pp. 136, 149-150; WORRAL (2004), pp. $223-$ 224. El problema que se presenta en este punto consiste en la pregunta respecto de si el tercero propietario inocente tiene o no derecho, según la $V$ Enmienda, a que conozca al jurado del proceso de comiso de su bien, si en algún caso el comiso pudiera resultar una pena infamante (como el comiso de bienes personales o indispensables), si la persona eventualmente sujeta a comiso puede acceder a un abogado que tenga conocimiento especializado suficiente para defenderlo en el proceso, o si es legítimo que la defensa del tercero inocente se encuentre en una situación donde éste deba autoinculparse de algún delito para defender la inocencia del bien que se le pretende decomisar.

${ }^{33}$ Enmienda VII: "En toda causa criminal, el acusado gozará del derecho de ser juzgado pública y expeditamente, por un jurado imparcial del Estado y distrito en que el delito se haya cometido, distrito que habrá sido determinado previamente por la ley; así como de ser informado sobre la naturaleza de la acusación; que se le caree con los testigos en su contra; que se le obligue a comparecer a los testigos en su favor y de contar con la ayuda de Asesoría Legal para su defensa".

34 Ann-Yu Chi (2003), pp. 1641-1643; Applebaum (2015), pp. 549-573; Douglas (1996), p. 572; Godfrey (2000), pp. 1699-1725. La pregunta es si el sujeto eventualmente decomisado tiene o no derecho a pagar con su patrimonio un abogado privado, entendiendo que su patrimonio puede contener dinero ilícito. La discusión consiste en si dicho dinero convierte a todo su patrimonio en uno ilícito, de tal forma que por el mismo sentido del comiso el sujeto no podría legítimamente pagar un abogado privado con ganancias ilegales. La cuestión de si esta última aseveración contraviene o no la garantía del derecho a defensa será tratada más adelante.

${ }^{35}$ Cassella (2003), pp. 342-349; Casella (2004), pp. 167 y 168; King (2012), p. 347; Wood (1994), pp. 1394-1398; WORRAL (2004), pp. 225-228. La pregunta es si la prohibición del bis in ídem incluye una prohibición de que el sujeto eventualmente víctima del comiso sea procesado en más de una sede de comiso (administrativo, civil o penal).

${ }^{36}$ Applebaum (2015), pp. 553-554; Farley (1994), pp. 152-154; Fishman (1994), pp. 129-132; JOHNSON (2002), pp. 1058-1059; MOORES (2009), pp. 783, 797-801; WORRAL (2004), pp. 228-229. La pregunta es si resulta legítimo que en el proceso de comiso penal sea el propietario del bien eventualmente decomisado quien debe probar su dominio del bien y que éste no se encontraba involucrado en un acto ilícito. 


\subsection{Comiso penal}

\subsubsection{Naturaleza del comiso penal}

Una primera aproximación al comiso penal (criminal forfeiture) lo presenta como la consecuencia de una pena. En este sentido, Cassella, siguiendo a la Corte Suprema de Estados Unidos, propone entenderlo como parte de una sentencia que condena penalmente ${ }^{37}$. No se trata, por tanto, de una pena accesoria, como lo considera la legislación nacional, sino la consecuencia de una condena, es decir, como la consecuencia directa de un ilícito. Se entiende como una acción in personam.

Las características del comiso penal y las razones de política criminal que lo sustentan permiten observar que sus objetivos son: (1) permitir que el cumplimiento de la ley no sólo se traduzca en un castigo sino en la recuperación de los bienes que constituyen el daño patrimonial, (2) detener los altos índices de criminalidad, (3) reducir el incentivo económico a cometer delitos, (4) extender las consecuencias pecuniarias desfavorables de participar en la actividad criminal y (5) desviar la propiedad hacia el erario público para hacer cumplir la ley ${ }^{38}$.

\subsubsection{Aspectos procesales}

Atendiendo a que las reglas procesales del comiso estadounidense son muy extensas, nos remitiremos a una explicación de las disposiciones más relevantes teniendo a la vista las carencias de nuestra legislación.

(a) La propiedad debe ser aquella directamente relacionada con la condena. Esto quiere decir que aquellos bienes sujetos a comiso por sentencia condenatoria deben limitarse a un delito acusado y condenado que haya sido cometido en un momento específico en el tiempo y espacio ${ }^{39}$. Todos los ilícitos que con fundada razón se crea que fueron cometidos antes o después de este período no podrán ser considerados a la hora del comiso. Esto puede presentar dos excepciones. Éstas son aquellos casos en que el imputado es acusado y condenado por un delito de conspiración

\footnotetext{
${ }^{37}$ La sentencia Libretti v. US (1995) generó la jurisprudencia al día de hoy dominante ("El comiso criminal es un elemento de la sentencia que deriva en una condena o en una declaración de culpabilidad"). En ese mismo sentido, US. v. Martin (2011), CASSELLA (2013), pp. 561-562. Hasta el año 2015 Libretti no ha sido sobre-reglada (overruled), es decir, la Corte Suprema no ha presentado una interpretación distinta para aquello que el comiso es, Applebaum (2015), p. 554.

38 Applebaum (2015), p. 555.

${ }^{39}$ En US v. Messino (2004), la Corte Suprema sostuvo que "debe existir una conexión entre la propiedad sujeta a comiso y la correspondiente actividad criminal". El problema más frecuente de esta limitación se observa cuando a propósito de la investigación de un delito se encuentran especies presumiblemente obtenidas por ilícitos similares pero cometidos con anterioridad. Tales objetos no pueden ser decomisados penalmente, CASSELLA (2013), pp. 565-566.
} 
(conspiracy). Todos los bienes relacionados a tal delito pueden ser decomisados, con independencia de si fueron cometidos en distintos espacios temporales pero con la misma finalidad. Por otro lado, en caso de que la parte que acusa alega y prueba la existencia de un plan. En tal caso, los bienes son decomisados aunque cada delito se haya cometido en un tiempo distinto, en el entendido de que todos fungían como medios para la comisión de un delito mayor ${ }^{40}$.

(b) Respecto juicio bifurcado, los tribunales en un caso puntual deberán determinar si el ente acusador ha logrado establecer el nexo entre el crimen bajo el cual se ha condenado y la propiedad que el Estado pretende decomisar. Pero el momento procesal para demostrar dicho nexo no dice relación con la instancia en que corresponde al órgano persecutor presentar la prueba (instancia denominada government case-in-chief) sino con la llamada fase de comiso ${ }^{41}$. La existencia de un juicio distinto al de culpabilidad permite una dedicación especial a la investigación y posterior justificación jurídica del adjudicador al momento de resolver, cuestión que mira en interés de preservar las garantías constitucionales de las partes envueltas en el proceso.

(c) Existe un momento probatorio para el comiso y otro para la culpabilidad de la persona por el hecho delictual. La valoración de la prueba para el comiso consiste en verificar si ésta permite establecer el nexo entre la propiedad y el delito bajo una regla de preponderancia de la evidencia y no de una apreciación más allá de toda duda razonable ${ }^{42}$. Si bien dicho estándar se mantiene a la fecha, la sentencia Apprendi v. New Jersey (2000) revivió la discusión. En ella la Corte Suprema de Estados Unidos plantea que los factores que incrementan la sentencia sobre la pena máxima indicada (statutory máximum) no son factores de la sentencia, sino elementos de un delito distinto ${ }^{43}$.

\footnotetext{
${ }^{40}$ Cassella (2013), pp. 567-568.

${ }^{41}$ La bifurcación está consagrada en la regla 32.2(b), la que sostiene que la Corte debe realizar una audiencia para determinar la posibilidad de decomiso sobre los bienes del acusado apenas se acepte la culpabilidad o exista una condena. Con anterioridad a esta regla las Cortes se dividían respecto a si el proceso bifurcado era necesario. Fue en los años '90 cuando comenzó a unificarse la jurisprudencia consensuada, que entendía que debía existir un juicio bifurcado con el fin de respetar la garantía de la $\vee$ Enmienda relativa a que el acusado pudiese guardar silencio durante el proceso de culpabilidad, pero testificar en defensa de su propiedad en el juicio de comiso, CASSELLA (2013), pp. 644-655.
}

${ }^{42}$ A pesar de la débil carga probatoria se ha entendido desde Libretti v. US (1995) a la fecha, que el derecho al veredicto de un jurado en el proceso de comiso no está protegido por la VI Enmienda. En contra de dicha interpretación ApplEBAum sostiene que sólo es posible compensar la facultad punitiva del Estado bajo un requisito probatorio tan feble acudiendo al jurado, alegando además que la interpretación de la VI Enmienda aplicada a estos casos varía en la judicatura de cada Estado, APPLEBAUM (2015), pp. 557-660.

${ }^{43}$ En este sentido, sostiene la Corte, el condenado tendría derecho según la VI Enmienda a que cualquier factor que incremente su sentencia sobre la pena máxima indicada sea suficiente para concederle un 
(d) La confiscación alternativa permite expandir el rango de acción del comiso. Una consecuencia importante del juicio al momento del comiso dice relación con que los bienes decomisables pueden ser sustitutos (por ejemplo, bienes que pertenecen al defendido pero no están ligados a la actividad criminal sobre la cual descansa éste). El adjudicador, cuando tenga fundada razón respecto que los bienes a decomisar pueden ser destruidos o hechos desaparecer, puede decretar la confiscación alternativa en dos formas: incluyendo la sustitución de bienes en la primera orden de comiso o modificando dicha orden en cualquier momento del juicio.

Una vez que la Corte o el jurado ha considerado procedente el comiso, deberá ingresar una orden preliminar de éste [18 U.S.C. § 32.2(b)(2)]. Dicha orden debe incluir una lista de los bienes directamente decomisables (cuyo paradero se conoce) y otra sobre los bienes decomisables que son parte del ilícito, pero aún no aparecen o se cree que puedan haberse disipado. Incluso, si el ente acusador sabe que el acusado tiene otros bienes que podrían reemplazar aquellos disipados, podrá incluir dicha propiedad en la lista. El comiso alternativo es un mandato legal dirigido al juez. Para evitar inconsistencias con el principio antes mencionado relativo a que los bienes decomisables son aquellos que se ven envueltos al momento del ilícito, deberá entenderse en realidad que es el monto de los bienes decomisables el que será fijado al momento del delito, de tal manera que puede el comiso operar sobre esos exactos mismos bienes u otros cuyo valor sea equivalente. En tal sentido, la propiedad envuelta en el delito en el momento preciso fija el monto del comiso, que podrá alcanzarse por diversas vías.

(e) Respecto la protección de la propiedad de terceros, es necesario indicar que, a pesar de que la legislación estadounidense protege la propiedad del tercero de buena fe, no es exactamente preciso señalar que sólo se puede decomisar los bienes de los cuales el defendido es propietario al momento en que el adjudicador solicita el comiso. La propiedad robada por el defendido no es precisamente su propiedad, del mismo modo que no lo son las ganancias de quien trafica droga o las del sujeto que lava dinero cuando éste es de propiedad de un tercero. De igual modo, la legislación permite el comiso de todos

juicio ante un jurado y la obligatoriedad del tribunal de probar más allá de toda duda razonable. Pese a que la parte defendida sostuvo posteriormente que Apprendi había sobre-reglado (over ruled) Libretti en estas materias, las cortes por unanimidad rechazaron tal versión. La sentencia Southern Union Company v. US (2012) ha sostenido que se debe establecer un monto máximo para el comiso, lo que permitirá que la parte defendida reclame que si el defendido puede alegar que se establezca un monto máximo frente a un jurado bajo una prueba más allá de toda duda razonable, entonces le asistiría el mismo derecho en lo relativo a la fase de comiso. De ser cierto, ello llevaría a que Libretti se encontrará sobre-reglada y las cortes probablemente se resistirán a ello, CASSELLA (2013), pp. 664, 667, 668. 
estos bienes como parte de la sentencia penal. Para los efectos de respetar las garantías constitucionales de los terceros propietarios de buena fe, el Congreso dispuso procedimientos post-proceso (denominado proceso auxiliar o ancillary proceeding) con el fin de determinar efectivamente quién es el propietario y eventualmente evitar que los bienes sean decomisados ${ }^{44}$.

A propósito del comiso penal y la participación de terceros propietarios de buena fe, la disposición 21 § 853(n) señala que, luego de la orden de comiso, el Estado debe publicar una noticia que indique los bienes que serán sujetos a éste. Podrá a su vez informar directamente a terceros sobre los cuales exista fundada sospecha de ser propietarios legítimos de dicha propiedad. Cualquier persona legítimamente interesada en recuperar un bien tendrá treinta días desde dicha publicación para presentar un recurso ante la Corte. Tal recurso deberá presentar los antecedentes que acrediten el dominio de la propiedad en cuestión, y la Corte tendrá un plazo de treinta días desde que es presentado para resolver si los bienes pertenecen al recurrente o, por el contrario, son sujetos a comiso bajo un juicio de preponderancia de la evidencia. De tratarse del primer caso, la Corte deberá modificar la sentencia de comiso y ordenar que el bien se restituya.

(f) Otras consecuencias del hecho de que el comiso sea parte de una sentencia tienen relación con que, al no ser una pena, la orden para ejecutarlo no vulnera la prohibición de doble criminalidad en los casos de extradición, no constituye bis in ídem en el proceso, no puede ser enmendada trascurridos siete días desde la sentencia y, de ser apelada, no puede hacerse sólo en parte, sino sobre la sentencia completa (en ambas fases) ${ }^{45}$.

\subsubsection{Principales discusiones basadas en comentarios a la legislación estadounidense}

(a) Carga de la prueba. Siendo el comiso criminal una parte de la sentencia penal entonces no puede operar sin una condena previa. La condena debe contener, en la fase de comiso, la prueba del nexo entre los bienes decomisados y el ilícito. El estándar exigido para ello es el de preponderancia de la evidencia (no el de más allá de toda duda razonable) según lo dispone 21 U.S. § 853(d). La misma carga probatoria tiene el acusado que quiera impugnar parte de la sentencia (n)(6). La justificación de dicho estándar radica en que, si el comiso penal es parte de una sentencia y si los demás factores incidentes en ella pueden ser probados por la Corte bajo preponderancia de la evidencia, entonces no

\footnotetext{
${ }^{44}$ Cassella (2013), pp. 575-576.

${ }^{45}$ Cassella (2013), p. 575.
} 
hay razón para pensar que los hechos fundados para probar la conexión entre la propiedad y el ilícito deban requerir de un baremo probatorio distinto ${ }^{46}$.

Pese a lo anterior, hay estados donde los estatutos permiten que, si hay una causa probable para creer que lo incautado es reconducible a tráfico de drogas, entonces la carga de la prueba se traslada al acusado para que pruebe lo contrario. Ello permite el congelamiento de cuentas corrientes e incautación de bienes por parte de las policías. Ese es el caso de los estatutos de Delaware, Florida, Massachusetts y Washington ${ }^{47}$.

(b) El proceso penal permite que, una vez que se pronuncie la sentencia que declara culpable al imputado (fase de culpabilidad), sus bienes puedan ser incautados con el fin de evitar que éstos puedan desaparecer, según $18 \S 32.2$ (b)(1) y (a)(b)(3). Esto lleva a que, en los casos en que se trate de dinero, las cuentas corrientes queden congeladas. Entonces se genera el problema respecto a cómo podría pagar el acusado un abogado privado sin cometer lavado de activos, y si ello se prohibiese, si acaso importa o no una vulneración al derecho a defensa y por ende al debido proceso. Parte minoritaria de la doctrina defiende la tesis de que no permitir el acceso a un abogado privado significaría una vulneración de la VI Enmienda ${ }^{48}$, en lo relativo a derecho a defensa, y a la $\mathrm{V}^{49}$ en tanto se estaría desequilibrando el poder en favor del Estado en contra el acusado. La Corte Suprema sentó un precedente con una solución y fundamentos distintos ${ }^{50}$. Al respecto, sostuvo: El estatuto de comiso (penal) no vulnera la garantía de la VI Enmienda que protege el derecho del acusado a elegir quien

\footnotetext{
${ }^{46}$ Así, US v. Bellomo (1999), US v. García-Guizar (1998), US. v. DeFries, US v. Patel (1997), US v. Voigt (1996), CASSELla (2013), pp. 663-664. La última sentencia en pronunciarse en la materia confirmando dicho estándar es Kaley et. vir. v. US (2013).

47 Applebaum (2015), p. 560.

${ }^{48}$ Enmienda VI: "En toda causa criminal, el acusado gozará del derecho a ser juzgado pública y expeditamente, por un jurado imparcial del Estado y distrito en que el delito se haya cometido, distrito que habrá sido determinado previamente por la ley; así como de ser informado sobre la naturaleza y causa de la acusación; que se le caree con testigos en su contra; que se obligue a comparecer a los testigos en su favor y de contar con la ayuda de Asesoría Legal para su defensa".

${ }^{49}$ Enmienda V: "Nadie estará obligado a responder de un delito castigado con la pena capital o con otra infame si un gran jurado no lo denuncia o acusa, a excepción de los casos que se presenten en las fuerzas de mar o tierra o en la milicia nacional cuando se encuentre en servicio efectivo en tiempo de guerra o peligro público; tampoco se pondrá a persona alguna dos veces en peligro de perder la vida o algún miembro con motivo del mismo delito; ni se le forzará a declarar contra sí misma en ningún juicio criminal; ni se le privará de la vida o la propiedad sin el debido proceso legal; ni se ocupará su propiedad privada para uso público sin una justa indemnización".

${ }^{50}$ Caplin v. Drysdale (1989), donde se sostuvo que el acusado no tenía un derecho a defensa privada, toda vez que no tenía derecho a pagarla con dinero que no le perteneciera, sin que lo anterior vulnere la VI Enmienda, LASKY (2014), pp. 1706-1707.
} 
lo represente. El acusado no tiene un derecho en la VI Enmienda a gastar el dinero de otro para pagar servicios de una defensa aunque estos bienes sean la única forma de que elija una defensa. Ese dinero, aunque en su posesión, no es correctamente suyo (...). Hay un fuerte interés estatal en recuperar completamente lo decomisado, dado que estos bienes van a un fondo que apoya los esfuerzos hechos por las oficinas para el cumplimiento de la ley. A su vez, el estatuto permite que los propietarios inocentes recuperen su propiedad, en razón de que uno de los mayores propósitos de la legislación de comiso es disminuir el poder económico del crimen organizado y los delitos de narcotráfico, incluyendo el uso de ese poder para conseguir defensas privadas ${ }^{51}$.

(c) Prohibición de bis in ídem (double jeopardy). La pregunta relativa a si existe una prohibición de bis in ídem se presenta en casos de converger procesos de comiso penal y civil. La cuestión dice relación con la (im)posibilidad de que, iniciado un proceso penal, el Estado siga a su vez un proceso de comiso civil para recuperar bienes que por cualquier motivo no pudieron ser recuperados en sede criminal. Pero se debe tener presente que, aun si se considerase que el comiso penal es un "castigo", el comiso civil no lo es, dado que es una acción sobre la cosa (in rem). Luego, no existe, en principio, un doble proceso ni doble punición en la eventualidad del caso anteriormente mencionado.

Estados Unidos tenía ya desde 1789 una larga tradición jurídica de estatutos federales que permitían la convergencia de penas y acciones de comiso in rem sobre los bienes involucrados en el delito. Tal es el caso de Various items of personal property v. US (1931), donde el imputado fue condenado por tener una propiedad que funcionaba como destilería (violando estatutos federales) y evadiendo impuestos. Cuando en el proceso se solicitó un requerimiento a la Corte Suprema por eventual bis in ídem, esta decretó que aquel no se configuraba. Por el contrario, asentó la siguiente jurisprudencia: "El comiso no es parte del castigo por un delito". La Corte concluyó que "lo dispuesto en la V Enmienda no es aplicable respecto bis in ídem ${ }^{52 " .}$

En One Lot Emerald Cut Stones v. US (1972) la Corte volvió a desestimar la vulneración de la $V$ Enmienda. El imputado estaba sujeto a un proceso penal por el contrabando de esmeraldas hacia Estados Unidos, y a su vez el Estado inició un proceso de comiso civil. La Corte Suprema sostuvo que el comiso civil no constituía un segundo proceso criminal ni un segundo castigo penal, expresando que el sistema de comiso civil estaba configurado como un recurso

\footnotetext{
${ }^{51}$ Caplin v. Drydale (1989).

52 Various Items of Personal Property (1931: 579, 581); CASSELla (2013), pp. 69-70.
} 
procesal para prevenir el contrabando en el país ${ }^{53}$. La distinción nuclear entre un proceso in rem y uno in personam además de la noción del comiso civil como recurso y el penal como consecuencia de un delito, permitían hacer operativos ambos procesos sin vulnerar garantías constitucionales.

Desde el año 1989, con US. v. Halper, la Corte Suprema sostuvo lo contrario, señalando que un proceso de comiso civil sobre un servicio médico ya condenado por fraude constituía un proceso suficientemente punitivo en su naturaleza como para constituir una infracción al bis in ídem de la $\mathrm{V}$ Enmienda. Posteriormente, en US. v. Austin (1993) la Corte Suprema sostuvo que el comiso civil equivale a una multa, y por lo tanto está sujeto a los límites de proporcionalidad establecidos en la VIII Enmienda ${ }^{54}$. La consideración del comiso civil como una multa y en algunos casos con naturaleza punitiva, tiene como consecuencia una confusión en la institución del comiso en lo relativo a cuál debería ser entonces el estándar de prueba para un comiso civil entendido como castigo, cuánto se extiende la $\mathrm{V}$ Enmienda en lo relativo a la prohibición de bis in ídem y cuál sería el rango de protección de la VIII Enmienda en lo que respecta a multas desproporcionadas.

Tres años más tarde, en US. v. Ursery (1996) se procesó al acusado por cometer, valiéndose de un inmueble, tráfico de drogas y lavado de activos, mientras el Estado se dirigió también contra sus bienes en una acción in rem. La Corte Suprema sostuvo que el comiso civil no era un castigo ni tenía naturaleza criminal para los efectos de bis in ídem a la luz de la $\vee$ Enmienda. Esto es, la Corte desestimó Austin y Halper y volvió a reglar sobre Various Items of Personal Property y One Lot Emerald Cut Stones.

(d) Destino de lo decomisado y compartir equitativo (equitable sharing). La notoria eficiencia del comiso estadounidense no sólo radica en el alto nivel de especialización de sus normas sino también en el sistema de incentivos que tiene la autoridad para que el procedimiento se ejecute. Este sistema consiste en que las ACL reciben un porcentaje de los montos decomisados (habitualmente de un $20 \%$ a $30 \%$ ) que sólo puede ser utilizado en mejorar la infraestructura o el equipamiento de la oficina. Ello aliviana la carga del Estado de gastar recursos públicos en ellas, pudiendo invertirlos en otras áreas ${ }^{55}$.

\footnotetext{
${ }^{53}$ One Lot Emerald Cut Stones v. US (1972: 236, 237); Cassella (2013), p. 71.

54 Barnet (2001-2), pp. 102, 209-210.

${ }^{55}$ HunTER detecta esto correctamente, sosteniendo que Estados Unidos no tenía los recursos públicos para combatir el crimen organizado, entonces se valió de un "sistema de financiamiento compartido" en un contexto donde la opinión pública estuvo de acuerdo con fortalecer al máximo las medidas que permitiesen el cumplimiento de la ley y previniesen la comisión de delitos de alta lesividad social, HunTER (2015), p. 556. Algunos comentaristas observan que el sistema de compartir equitativo se
} 
Con la finalidad de limitar el poder punitivo estatal manifestado en el comiso, la jurisprudencia estadounidense ha elaborado lo que se conoce como el Matthews test ${ }^{56}$. Según éste, el tribunal al momento de decomisar deberá: (i) detectar cuál es el interés del privado en juicio, (ii) determinar el riesgo de que ocurra una eventual expropiación errónea de los bienes y cuál es la posibilidad de tomar una medida alternativa distinta al comiso que permita un mismo resultado, y (iii) propender a que el aparato estatal, incluyendo los fiscales y las cargas administrativas, permitan que se logre esa medida alternativa. Ello ha hecho posible equilibrar razonablemente la potestad estatal de decomisar y su correlativa materialización de justicia con las garantías constitucionales de los implicados en el proceso.

\section{El comiso en la legislación estadounidense como horizonte para nuevas reglas de derecho penal chileno}

Luego de revisar el sistema de comiso penal en la legislación estadounidense, expondremos un análisis comparativo entre éste y lo propuesto por el PNCP, para de este modo elaborar un horizonte normativo que importe determinadas sugerencias de lege ferenda a la legislación. En esta parte se revisará lo dispuesto por el PNCP para la situación del comiso sobre terceros propietarios inocentes, la carencia de un comiso de ahorro de costos, la omisión del proyecto sobre el problema del pago a los abogados y, finalmente, el problema del destino que deben tener los bienes decomisados.

\subsection{El comiso a terceros inocentes}

El articulado del PNCP mantiene una regla general del artículo 31 del Código Penal: no se puede decomisar la propiedad de terceros inocentes ${ }^{57}$. El hecho

puede prestar para incentivos perversos, ANN-Yu CHI (2003), p. 1636; MOORES (2009), p. 784; MURPHY (2010), p. 87; TURNER (1995), pp. 182-187. Otros han sugerido que el monto de lo decomisado vaya a escuelas públicas, instituciones de adopción o a la creación de fondos para programas de prevención de drogas, ANn-Yu CHI (2003), p. 1671; CRAWFORD (2015), p. 281.

56 HigGins (2011), pp. 795-796.

${ }^{57}$ Art. 127. "Comiso de instrumento de libre uso. El comiso de las cosas de libre uso que hubieren sido empleadas como instrumento en la comisión del delito sólo será impuesto respecto del propietario de la cosa que es condenado a una pena como responsable del delito". Art. 133 inciso $3^{\circ}$. "Comiso de instrumento de uso legalmente restringido. Con todo, no podrá imponerse el comiso de una cosa cuyo propietario no hubiere tenido conocimiento de su empleo como instrumento para la comisión del hecho, antes o durante su comisión, o al momento de adquirirlo con posterioridad a la comisión del hecho". Art. 134 inciso $3^{\circ \prime \prime}$. Comiso de efectos. Con todo, no podrá imponerse el comiso de una cosa cuyo propietario no hubiere tenido conocimiento de su producción u obtención mediante o con ocasión de la comisión del hecho, o al momento de adquirirlo a título oneroso con posterioridad a 
de que no se pueda privar de la propiedad a terceros que no participaron de la comisión del delito ni tuvieron noticias de él, es algo indiscutible. La cuestión radica en si la protección de los terceros de buena fe debe traducirse en que la ley penal establezca una prohibición de decomisar o si la ley debe autorizarlo pero concediéndoles con posterioridad en el proceso una acción para demostrar su inocencia y recuperar sus bienes. Se trata de cuál es el momento en que se materializa la protección del patrimonio de terceros inocentes.

Si la protección del patrimonio de terceros inocentes se encuentra dada de manera adelantada, es decir, que la propia ley prohíba su decomiso (como propone el PNCP) se estaría incrementando la posibilidad de que el delincuente salve parte del dinero ilícito mediante "palos blancos". Bastaría con que una persona simule exitosamente ser un tercero propietario de buena fe para que la propia ley prohíba el decomiso de esos bienes. En cambio, si dicha protección se encuentra dilatada, esto es, que la ley permita el comiso de bienes pertenecientes a terceros de buena fe pero en una instancia procesal posterior conceda el derecho al propietario para recuperar su bien, entonces se disminuye la posibilidad de que el hechor se valga de "palos blancos" para rescatar parte de los bienes obtenidos ilícitamente. La reducción de la posibilidad de burlar la ley radica en que en el segundo caso quien acuda a recuperar sus bienes deberá hacerse parte de un proceso judicial, lo que requerirá tiempo y recursos y terminaría por desincentivar la conducta.

Lo anterior no constituye una desprotección hacia el tercero propietario de buena fe en materia de garantías constitucionales, particularmente, respecto el principio de culpabilidad y la presunción de inocencia, ello, atendiendo a que aquella modificación que proponemos no se trata de privar al tercero de su propiedad de manera inapelable, sino de retrasar la instancia en la cual el ordenamiento legal materializa dicha garantía. De lo que se trata, en realidad, es de transferir el costo procesal al tercero inocente en beneficio del sistema global de comiso penal. Esto quiere decir que en principio la ley permitirá decomisar dichos bienes, en su defecto el propietario podrá reclamarlos. Una configuración de esa índole permitiría que aumenten los montos decomisados.

Una propuesta como la mentada se condice con la regla general del comiso penal estadounidense: la propiedad de terceros inocentes puede ser decomisada, sin perjuicio de que el tercero mantenga acciones post-proceso (Ilamado

ello". Artículo 137 PNCP "Ganancias distribuidas a terceros de buena fe. No podrá imponerse el comiso respecto de las ganancias obtenidas por o para una persona jurídica y que hubieren sido distribuidas entre sus socios, accionistas o beneficiarios que no hubieren tenido conocimiento de su procedencia ilícita al momento de su adquisición. En tal caso, la ganancia distribuida podrá considerarse para la determinación de la pena de multa correspondiente a imponer". 
procedimiento auxiliar o ancillary proceeding) con la finalidad de que tenga una instancia para reclamar legítimamente sus bienes ${ }^{58}$.

La justificación de traspasar el costo procesal al tercero de buena fe radica en que las personas son responsables sólo de la conservación de su patrimonio,. lo son también de verificar, al momento de adquirirlo, que no provengan de un delito así como de ser diligentes para que no sean utilizados por otros para cometer ilícitos. En ese contexto, se presume que quien sufrió el hecho de que su propiedad se hubiera encontrado involucrada en un delito por un tercero, tiene en principio la responsabilidad de no haber tenido el debido cuidado al momento de prevenir que ello ocurriera. Y en caso de que dicha diligencia hubiese sido supererogatoria, suponiendo que no existía responsabilidad alguna de parte del tercero propietario de buena fe, entonces queda la posibilidad de que la persona se haga parte en juicio con posterioridad al comiso y recupere sus bienes.

\subsection{Extensión de la propiedad decomisable: el ahorro de costos}

El artículo 134 PNCP ha echado algunas luces sobre la extensión del comiso de ganancias. Siendo eso cierto en contraste con lo dispuesto en el Código Penal, persisten algunos aspectos que nos parecen no clarificados. La extensión del comiso definida por la Corte Suprema de Estados Unidos parece más hosca, pero más extensiva en algunos casos. Como se ha sostenido, ésta ha definido las ganancias como "la propiedad que un sujeto no habría obtenido o retenido sino por la comisión de un delito" (US. v. Warshack, 2010). A pesar de ser una definición poco meticulosa, tiene la externalidad positiva de incluir en ella el comiso de las ganancias obtenidas por ahorro de costos (cost savings). El PNCP nada dice sobre ello.

Una acción delictual puede no importar una ganancia exclusivamente porque genera dinero sino porque evita que este se gaste, es decir, permite ahorro. Ese es el caso emblemático de delitos que tienen el medioambiente como bien jurídico protegido. Considérese el delito de tráfico de residuos peligrosos de la Ley $\mathrm{N}^{\circ} 20.920^{59}$. La persona que comete el delito mentado puede obtener una ganancia no sólo en la hipótesis de que venda dichos residuos, sino en el

\footnotetext{
${ }^{58}$ Respecto la forma en que el comiso penal estadounidense trata la cuestión, véase supra 2.2.2 (e).

${ }^{59}$ Art. 44 PNCP "Responsabilidad penal por tráfico de residuos peligrosos. El que exporte, importe o maneje residuos peligrosos, prohibidos o sin contar con la autorización para ello será sancionado con la pena de presidio menor en su grado mínimo a medio.

Si además la actividad ha generado algún tipo de impacto ambiental se aplicará la pena aumentada en un grado".
} 
caso de que ejecute esta acción de manera recurrente para ahorrar el costo que significa trasladar y depositar esos residuos conforme la ley lo indica.

La disposición relativa al comiso de ganancias del PNCP tiene como verbos rectores la obtención de ganancias, la acción de originar utilidad y el acto de adquirir ganancias ${ }^{60}$. Dichos verbos son activos, describen la conducta de ejecutar una acción cuya finalidad es incorporar algo al propio patrimonio. No se trata propiamente de verbos rectores que se refieran a retener o ahorrar bienes valiéndose de un delito. Una aplicación estricta del vigente artículo 31 del Código Penal o del artículo 136 del PNCP no permitiría decomisar los ahorros de costos que pueda importar la comisión de determinados ilícitos medioambientales.

La judicatura estadounidense ha entendido que, en base a la definición extensiva que la Corte Suprema dio al comiso, éste incluye en la locución ganancias los bienes que se han retenido como consecuencia de un ilícito ${ }^{61}$. Se trata de una labor interpretativa conjunta entre ésta y el legislador. Atendiendo a nuestra tradición jurídica, será relevante que sea el legislador quien solucione explícitamente esta cuestión, máxime considerando que la intervención jurídico penal ha sido crecientemente reclamada para la protección del medioambiente.

\subsection{Pago a abogados particulares}

El proceso de comiso presenta la pregunta respecto a la legitimidad del pago de abogados particulares por parte del imputado. Puede ocurrir que los bienes de la persona contra la cual se esté siguiendo el proceso queden congelados en una cuenta bancaria, surgiendo la pregunta acerca de si es legítimo liberar el monto exacto para que el imputado pague a un abogado particular o si debe recurrir a la defensoría penal pública.

\footnotetext{
${ }^{60}$ Art. 136 PNCP Comiso de ganancias. "El comiso de bienes por un valor equivalente a las ganancias que se hubiere obtenido directa o indirectamente mediante la comisión de un hecho, con ocasión de su comisión, o para o por cometerlo, procederá respecto de toda clase de hechos ilícitos conminados con una pena.

Las ganancias se extienden a los frutos obtenidos y a las utilidades que se hubieren originado, cualquiera que sea su naturaleza jurídica. Se extienden también a todo aquello que se hubiere adquirido en lugar de las ganancias directas o indirectamente obtenidas, ya sea mediante su enajenación o como compensación por su pérdida, o en razón del ejercicio del derecho que se hubiere obtenido como ganancia.

Las ganancias se extienden asimismo a lo que hubiere obtenido, en los términos señalados por los incisos precedentes, una persona que no intervino en el hecho respectivo, si el interviniente hubiere actuado en su beneficio".

${ }^{61}$ Cassella (2013), p. 902.
} 
En caso de conceder que se libere parte de los bienes para poder pagar un abogado particular, se estaría dando el caso de que se podría estar cometiendo un delito de lavado de activos según los artículos 27 y 28 de la Ley N 19.913 y se podría presentar el absurdo de que una persona no sólo se enriquezca con su propio dolo sino que además se defienda a costas de él.

Teniendo presente que ambas cuestiones no son exclusivamente un problema relativo al PNCP y difícilmente podría esperarse una solución privativa de la labor de redactar un nuevo código, podría lograrse un significativo avance en el esclarecimiento de estas cuestiones con una disposición que exponga cuál es la extensión de la limitación del imputado para acceder a una defensa en caso de encontrarse un proceso de comiso, con el congelamiento de bienes correlativo, en su contra.

La forma como se ha dado la discusión en Estados Unidos respecto el congelamiento de cuentas, el acceso a una defensa privada y el comiso, ha dividido a los comentaristas y la judicatura. Una parte minoritaria de los primeros considera que no conceder el derecho a contratar a un abogado particular bajo el argumento de que los bienes están congelados en un proceso de comiso contraviene la sexta enmienda ${ }^{62}$. Pero la Corte Suprema sentó un antecedente distinto: El estatuto de comiso (penal) no vulnera la garantía de la VI Enmienda que protege el derecho del acusado a elegir quien lo represente. El acusado no tiene un derecho en la VI Enmienda a gastar el dinero de otro para pagar servicios de una defensa aunque estos bienes sean la única forma de que elija una defensa. Ese dinero, aunque en su posesión, no es correctamente suyo (...). Hay un fuerte interés estatal en recuperar completamente lo decomisado, dado que estos bienes van a un fondo que apoya los esfuerzos hechos por las oficinas para el cumplimiento de la ley. A su vez, el estatuto permite que los propietarios inocentes recuperen su propiedad, en razón de que uno de los mayores propósitos de la legislación de comiso es disminuir el poder económico del crimen organizado y los delitos de narcotráfico, incluyendo el uso de ese poder para conseguir defensas privadas ${ }^{63}$.

${ }^{62}$ VI Enmienda. "En toda causa criminal, el acusado gozará del derecho de ser juzgado pública y expeditamente, por un jurado imparcial del Estado y distrito en que el delito se haya cometido, distrito que habrá sido determinado previamente por la ley; así como de ser informado sobre la naturaleza y causa de la acusación; que se le caree con los testigos en su contra; que se obligue a comparecer a los testigos a su favor y contar con la ayuda de asesoría legal para su defensa".

${ }^{63}$ Caplin v. Drysdale (1989), pp. 624-633, donde se sostuvo que el acusado tenía un derecho acotado a defensa, toda vez que no tenía derecho a pagarla con dinero que no le pertenece, sin que lo anterior vulnere la VI Enmienda, LASKY (2014), pp. 1706-1707. Para ver los términos de la discusión antes de CAFRA: KAAS (1990), pp. 369-370. 
EL COMISO PENAL EN LA LEGISLACIÓN ESTADOUNIDENSE COMO

horizonte comparativo frente al Proyecto de Nuevo Código Penal

En el ordenamiento jurídico nacional la garantía constitucional sobre debido proceso del artículo $19 \mathrm{~N}^{\circ} 3$, se refiere al derecho a defensa jurídica y al derecho irrenunciable a que toda persona sea asistida por un abogado defensor proporcionado por el Estado. Ello basta para satisfacer el derecho a defensa, sin que la ley exija que el abogado deba ser uno particular. Por tanto la prohibición de liberar los bienes del procesado sujeto eventualmente a comiso para pagar un abogado particular no contraviene la garantía constitucional citada. La disposición mentada ampara al imputado en su derecho a defensa, no en la acción de costearla con bienes que presuntamente no le pertenecen.

\subsection{Destino de lo decomisado}

El artículo 60 del Código Penal establece el destino de lo decomisado una vez que los bienes se encuentren en el erario fiscal ${ }^{64}$, mientras el PNCP nada dice. La forma en que el PNCP resuelve la cuestión es insuficiente por dos motivos. El primero, por no existir un reglamento que estipule la forma en que dichos montos deben ser gastados por parte del Estado, por lo que el control que exista sobre aquellos activos una vez que sean decomisados será difuso. El segundo motivo es que no existen disposiciones legales, sean procesales penales o civiles, que dispongan el procedimiento mediante el cual las víctimas de los delitos que dieron pie al comiso puedan recuperar sus bienes antes de que éstos se confundan con el patrimonio fiscal una vez ejecutado el comiso ${ }^{65}$.

\footnotetext{
${ }^{64}$ Artículo 60 Código Penal. "La multa se considera como la pena inmediatamente inferior a la última en todas las escalas graduales. Para fijar su cuantía respectiva se adoptará la base establecida en el art. 25, y en cuanto a su aplicación a cada caso especial se observará lo que prescribe el art. 70 . El producto de las multas, ya sea que se impongan por sentencia o que resulten de un decreto que conmuta alguna pena, ingresará a una cuenta fiscal, especial, contra la cual sólo podrá girar el Ministerio de Justicia para algunos de los siguientes fines, y en conformidad al Reglamento que para tal efecto dictará el Presidente de la República: 1. Creación, instalación y mantenimiento de establecimientos penales y de reeducación de antisociales; 2. Creación de Tribunales e instalación, mantenimiento y desarrollo de los servicios judiciales, y 3. Mantenimiento de los Servicios del Patronato Nacional de Reos. La misma regla señalada en el inciso anterior, se aplicará respecto a las cauciones que se hagan efectivas, de los dineros que caigan en comiso y del producto de la enajenación en subasta pública de las demás especies decomisadas, la cual se deberá efectuar por la Dirección de Aprovisionamiento del Estado. Las disposiciones de los dos incisos anteriores no son aplicables a las multas señaladas en el artículo 483-b. El producto de las multas, cauciones y comisos derivados de faltas y contravenciones, se aplicará a fondos de la Municipalidad correspondiente al territorio donde se cometió el delito que se castiga".

${ }^{65}$ El Código Penal expresa a qué instituciones irán los bienes, pero a la fecha no existe un control riguroso respecto en qué se gastan ni cuánto es el monto decomisado anualmente. Respecto las acciones de
} 
El PNCP ofrece un avance en esta materia, aunque insuficiente. El artículo $139^{66}$ genera una regla de acción civil de las víctimas para la recuperación de los bienes decomisados, pero no esclarece cuestiones de primera relevancia. No existe nitidez respecto de cómo operaría tal acción. No hay claridad respecto a la naturaleza de esa acción, sea una de índole procesal penal o de procedimiento civil. Dicha disposición nada dice respecto de la existencia de una prelación de pago sobre el monto decomisado en caso de que haya sido más de una persona la perjudicada por el delito contra el patrimonio. Tampoco existe claridad, de existir intervención delictiva múltiple en la comisión del delito, sobre si se emitirá una orden de comiso por el monto total del perjuicio a cada uno de los intervinientes o, si se establecerá una orden por un monto proporcional al grado de intervención en el injusto.

Uno de los problemas que subsiste hasta el día de hoy en la legislación vigente, radica en que a veces la fiscalía debe retardar la aplicación del artículo 31 del Código Penal exclusivamente para que los bienes no sean decomisados y así no vayan directamente al fisco, con la finalidad de que antes se puedan establecer acciones y compensaciones espurias por parte del victimario hacia las víctimas, evitando así que un comiso insuficientemente reglado lleve a que los bienes se integren al erario público sin alcanzar a ser restituidos a las víctimas.

En Estados Unidos el interés del ofendido en que se ejecute el comiso para recuperar sus bienes se encuentra amparado en una acción de restitución en el comiso penal. Dicha acción es operativa en conjunto con la de comiso y puede ser por un monto diferente. No existe vulneración de garantías constitucionales por el hecho de que el condenado deba desembolsar dinero por el comiso penal frente al fisco y además por la restitución hacia la víctima, y en caso de que el delito que cometió haya tenido al Estado como perjudicado, tampoco habrá doble pago al concurrir ambas ${ }^{67}$.

La distinción anterior tiene su fundamento en la hipótesis de que una persona obtenga un monto de dinero producto de un ilícito y con el paso del tiempo utilice ese monto para ganar mayores utilidades. En tal caso, la acción de restitución debe recaer sobre el monto del dinero obtenido en el delito y ser restituida a la víctima, y las utilidades que de ello derivaron, al fisco.

las víctimas para recuperar sus bienes antes de que sean traspasados al fisco, no existen disposiciones claras en la normativa vigente.

${ }^{66}$ Art. 139 PNCP "Acción civil de la víctima. La acción civil de la víctima del delito podrá ejercerse sobre los bienes decomisados conforme a las disposiciones de los Párrafos 2 y 3 de este título".

${ }^{67}$ Cassella (2013), p. 725. 
El COMISO PENAL EN LA LEGISLACIÓN ESTADOUNIDENSE COMO

horizonte comparativo frente al Proyecto de Nuevo Código Penal

\section{Conclusiones}

Este trabajo ha tenido por finalidad explicar las reglas de un sistema de comiso penal complejo, como es el de Estados Unidos, en cotejo con las disposiciones propuestas por el PNCP y con aquellas vigentes en Chile. Lo anterior encuentra su justificación en el alcance limitado de las reglas decimonónicas vigentes sobre dicha materia frente a la creciente sofisticación de la organización criminal. A su vez, en que la importante labor en comisión para la redacción de un nuevo Código Penal requiere de estudios comparados avanzados para tratar correctamente un tema como el comiso.

Se ha ofrecido una exposición de la escasa discusión de la dogmática nacional respecto al comiso en la ley penal vigente, del desarrollo normativo y de la discusión jurisprudencial en EE.UU. y un análisis comparado entre lo dispuesto en las reglas de dicho país y lo propuesto por el PNCP. Teniendo como criterio rector la idea de que una correcta legislación de comiso debe ser expansiva y especializada, y considerando que la institucionalidad jurídica estadounidense tiene principios constitucionales-penales comunes que la hacen asimilable con la nacional, se han elaborado algunas conclusiones.

La primera es que la forma en que la ley vigente y el PNCP tratan la situación en que queda el tercero propietario inocente de un bien eventualmente decomisado es insuficiente. La prohibición legal de decomisar los bienes de los terceros favorece a quienes burlan las leyes de confiscación valiéndose de "palos blancos", es decir, transfiriendo bienes obtenidos ilícitamente a otras personas que reclaman no haber tenido conocimiento de su proveniencia delictual. Se propone que dicho comiso sea permitido legalmente, pero que en una instancia procesal posterior el tercero propietario inocente, ejerza su derecho a recuperar su(s) bien(es) acreditando el dominio sobre ellos y su desconocimiento del origen ilícito de ellos. Ello se condice con la idea de que se debe ser responsable al momento de adquirir bienes para saber de dónde provienen, o de preservar aquellos que ya se poseen, para evitar que terceros los usen para cometer injustos.

La segunda es una crítica a la ausencia de definición del comiso de ganancias por parte de la legislación vigente y de la propuesta por el PNCP. En ambos casos queda excluida la hipótesis de las ganancias ilícitas mediante ahorro de costos. Verbos rectores tales como obtener u originar se condicen con el verbo relativo a ejecutar acciones y no con retener o ahorrar bienes valiéndose de un delito. Ello relega a la imposibilidad de decomisar, por ejemplo, los montos que empresas públicas o privadas ahorren al cometer delitos medioambientales al momento de desechar residuos.

La tercera crítica se refiere a la omisión de la normativa penal vigente así como del PNCP respecto el problema del pago de abogados en casos en que los fondos de un sujeto eventualmente víctima del comiso se encuentren 
congelados. La pregunta fundamental es si el procesado en dicha situación tiene derecho a que se libere parte de su patrimonio para pagar un abogado particular amparado en la garantía constitucional del debido proceso o si, la intensidad del comiso es tan relevante que todos los bienes eventualmente sujetos a éste deben permanecer intactos hasta el momento de la ejecución de la sentencia, quedando al imputado exclusivamente la asistencia del defensor penal público. Siguiendo la normativa e interpretación estadounidense, hemos sostenido que la garantía constitucional del debido proceso materializada en el derecho a defensa, asegura el acceso a un abogado defensor pero no a pagar una defensa particular con bienes obtenidos de forma presuntamente ilícita.

Finalmente, se previene que tanto la normativa vigente como el PNCP carecen de una solución para el destino de lo decomisado, siendo insuficiente por dos motivos. Por un lado, no existe una referencia a un reglamento que estipule la forma en que dichos activos deben ser gastados ni qué institución estará a cargo de hacer un seguimiento de ello. Por otro, no se hace mención a disposiciones normativas que se refieran a la forma en que las víctimas de delitos que vieron mermado su patrimonio puedan interponer acciones para recuperar sus bienes. En el primer punto el riesgo es que los activos se difuminen en el aparato público y no se logren optimizar esos recursos. En el segundo punto, las víctimas corren peligro de no alcanzar a que sus bienes sean restituidos antes de que éstos sean transferidos al patrimonio fiscal. De ocurrir cualquiera de ambas situaciones se estaría erosionando el sentido del comiso.

\section{Bibliografía CITADA}

AnANías Zaror, Ignacio (2014): "El comiso de ganancias", en: Revista de Estudios de la Justicia ( $\left.\mathrm{N}^{\circ} 21\right)$, pp. 183-186.

ANN-Yu CHI, Karis (2003): "Follow the money: getting to the root of the problem with civil asset forfeiture in California", en: California law review ( $\mathrm{N}^{\circ}$ 90), pp. 1635-2002.

Applebaum, Brynn (2015): "Criminal asset forfeiture and the sixth amendment after southern union and alleyne: state level ramifications", en: Vanderbilt law review (Volumen 68, № 2), pp. 549-573.

BARNET, Todd (2001): "Legal fiction and forfeiture: An historical analysis of the civil forfeiture reform act", en: Duquesne law review (Volumen 40), pp. 77-109.

Boucht, Johan (2017): The limits of asset confiscation (Oxford and Portland, Hart Publishing).

Cassella, Stefan (2001): "The civil asset forfeiture reform act of 2000: expanded government forfeiture authority and strict deadlines imposed on all parties", en: Journal of Legislation (Volumen 27, № 1), pp. 97-152. 
El COMISO PENAL EN LA LEGISLACIÓN ESTADOUNIDENSE COMO horizonte comparativo frente al Proyecto de Nuevo Código Penal

(2003): "Development of asset forfeiture in the United States", en: Criminal justice in a new society (Volumen 314), pp. 314-359.

(2004): "Overview of asset forfeiture law in the United States", en: South African Journal of Criminal Justice (Volumen 17), pp. 347-367.

(2013): Asset forfeiture law in the United States (New York, Juris Publishing).

Couso Salas, Jaime y Hernández Basualte, Héctor (2011): Código Penal comentado. Parte general, $1^{\text {a }}$ edición (Santiago, Editorial Abeledo Perrot).

Crawford, Andrew (2015): "Civil asset forfeiture in Massachusetts: a flawed incentive structure and its impact on indigent property owners", en: Boston College Journal of Law and Social Justice (Volumen 35), pp. 257-284.

Cury UrzúA, Enrique (2005): Derecho Penal. Parte General, 9a edición (Santiago, Editorial PUC).

DALEY, Patrick (2004-5): "Civil asset forfeiture: an economic analysis of Ontario and British Columbia", en: Western journal of legal studies (Volumen 5), pp. 1-24.

Douglas, Kim (1996-7): "Asset forfeiture: giving up your constitutional rights", en: Campbell law review (Volumen 19), pp. 527-578.

Etcheberry Orthusteguy, Alfredo (1998): Derecho Penal. Parte General (Santiago, Editorial Jurídica).

FISHMAN, George (1994): "Civil asset forfeiture reform: the agenda before congress", en: New York Law School Law Review (Volumen 39), pp. 121-147.

Garrido Montt, Mario (2001): Derecho Penal. Parte General (Santiago, Jurídica).

GiBSON, David (2011): "Spreading the wealth: is asset forfeiture the key to enticing local agencies to enforce federal drug laws", en: Hastings Constitutional Law Quarterly (Volumen 39), pp. 569-592.

Godfrey, Lindsey (2000-1): "Rethinking the ethical ban on criminal contingent fees: A commonsense approach to asset forfeiture", en: Texas Law Review (Volumen 79), pp. 1698-1725.

Gordon, Tom (1998): "Civil asset forfeiture: procedural and economical inequities", en: Guild Practitioner (Volumen 188), pp. 188-198.

GuZMÁn DÁlbORA, José Luis (2009): La pena y la extinción de la responsabilidad penal (Buenos Aires, Editorial B de F).

HigGins, Kasey (2011): "Shiver me timbers: asset forfeiture crime", en: Phoenix Law Review (Volumen 4), pp. 771-797.

HuNTER, Isaiah M. (2015): "The war on drugs and taxes: how tax expenditure analysis can shed light on civil asset forfeiture", en: New York University Journal of Law and Liberty (Volumen 9), pp. 549-579. 
JOHNSON, Barclay Thomas (2002): "Restoring civility: the asset forfeiture reform act of 2000: baby steps toward a more civilized civil forfeiture system", en: Indiana Law Review (Volumen 35), pp. 1045-1083.

KaAS, Glenn (1990): "Recent developments in the Connecticut Drug Asset Forfeiture law", en: Bridgeport Law Review (Volumen 11), pp. 365-370.

KING, Colin (2012): "Using civil process in pursuit of criminal law objectives: a case-study of non-conviction-based asset forfeiture", en: International Journal of Evidence \& Proof (Volumen 16), pp. 337-363.

Labatut Glena, Gustavo (1979): Derecho penal. Parte general (Santiago, Editorial Jurídica).

LASKY, Matthew R. (2014): "Imposing indigence: reclaiming the qualified right to counsel of choice in criminal asset forfeiture cases", en: Journal of Criminal Law and Criminology (Volumen 104), pp. 165-194.

McCAw, Catherine (2000): "Asset forfeiture as a form of punishment: a case for integrating asset forfeiture into criminal sentencing", en: American Judicial Criminal Law (Volumen 38), pp. 181-220.

MOORES, Eric (2009): "Reforming the civil asset forfeiture reform act", en: Arizona Law Review (Volumen 51), pp. 777-803.

Murphy, Mary (2010): "Race and civil asset forfeiture: a disparate impact hypothesis", en: Texas journal on civil liberties and rights (Volumen 16, № 1), pp. 77-100.

Novoa Monreal, Eduardo (2010): Curso de derecho penal chileno. Parte General, $3^{a}$ edición (Santiago, Editorial Jurídica).

Politoff Lifschitz, Sergio; Matus Acuña, Jean, y Ramírez Guzmán, María (2002): Lecciones de derecho penal chileno. Parte general (Santiago, Editorial Jurídica).

RuI, Jon y Sieber, Ulrich (2015): Non-conviction-based confiscation in Europe (Berlín, Editorial Duncker \& Humbolt).

SKORUP, Brent (2013): "Ensuring eight amendment protection from civil asset forfeiture in California", en: Civil rights law journal (Volumen 22), pp. 427-458.

Suárez Crothers, Christian (2000): "Análisis constitucional y legal de las penas de confiscación y comiso en el Código Penal y en la ley de estupefacientes", en: Politoff, Sergio y Matus, Jean Pierre (coords.), Gran criminalidad organizada y tráfico ilícito de estupefacientes (Santiago, Editorial Jurídica ConoSur).

TURNER, Lynae Trista (1995): "Racial disparity in the development of the drug courier profile and civil asset forfeiture provisions", en: Justice Law Review (Volumen 183), pp. 183-207. 
El COMISO PENAL EN LA LEGISLACIÓN ESTADOUNIDENSE COMO horizonte comparativo frente al Proyecto de Nuevo Código Penal

UnidAD de ANÁlisis FinanCIERO (2016): "Informe estadístico 2016". Disponible en: https://www.uaf.cl/descargas/estadisticas/Informe_Estadistico_2016.pdf [visitado el 28 de marzo de 2017].

WILSON, Derrick (1991): "Drug asset forfeiture: in the war on drugs, is the innocent spouse the loser", en: Journal of Family Law (Volumen 30), pp. 135-153.

Wood, Cynthia (1994): "Asset forfeiture and the excessive fine clause: an epilogue to Austin v. United States", en: Wake Forest Law Review (Volumen 29), pp. 1357-1403.

WORRAL, John (2004): "A civil asset forfeiture reform act of 2000: a sheep in wolf clothing?", en: PIJPSM (Volumen 27), pp. 220-240.

ZaGARIS, Bruce y KINGMA, Elizabeth (1991): "Asset forfeiture international and foreign law: an emerging regime", en: Emory International Law Review (Vol. 5), pp. 445-530.

\section{JURISPRUDENCIA CITADA}

Augusto Pinochet y otros (2004): Corte de Apelaciones de Santiago, 21 de junio de 2017 (malversación de caudales públicos).

Carlos Silva Leiva y otros (2012): Corte Suprema, 25 de junio de 2012 (tráfico ilícito de estupefacientes).

Julián Moreno de Pablo y otros (2015): Tribunal Oral en lo Penal de Santiago, 18 de diciembre de 2015 (estafa, infracción a la ley de mercado de valores, falseamiento de estados contables y lavado de activos).

\section{JURISPRUDENCIA ESTADOUNIDENSE CITADA}

Apprendi v. New Jersey, 530 U.S. 466 (2000), 18-5(d).

Austin v. United States, 509 U.S. 602 (1993), 2-2, 2-3, 2-5, 2-9(a), 2-9(b), 2-10(a), 2-12, 28-2.

Bellomo, United States v., 176 F.3d 580 (2d Cir. 1999), 18-5(d).

Caplin \& Drysdale, Chartered v. United States, 491 U.S. 617 (1989), 2-12, 17-7, 21-2, 23-16(c).

DeFries, United States v., 129 F.3d 1293 (D.C. Cir. 1997), 18-5(d), 19-5, 25-4(a), 25-4(d).

García-Guizar, United States v., 160 F.3d 511 (9 ${ }^{\text {th }}$ Cir. 1998), 15-3(b), 18-2, 18-5(d), 25-5(a).

Halper, United States v., 490 U.S. 435 (1989).

Kaley et. vir., United States v., 588 U.S. 677 (2013), f3(d). 
Libretti v. United States, 516 U.S. 29 (1995), 1-4(b), 15-2, 18-3(b), 18-4(a), 18-5(d). Martin, United States v., 662 F.3d $301\left(4^{\text {th }}\right.$ Cir. 2011) 13-8, 14-4, 15-2, 17-2, 185(d), 20-3(d), 20-8.

Messino, United States v., 382 F.3d 704 (7th Cir. 2004), 15-3(b), 18-4(a), 18-5(d).

One Lot Emerald Cut Stones v. United States, 409 U.S. 232 (1972), 1-5(a)(2), 2-4, 2-10(a), 14-3.

Patel, United States v., 131 F.3d 1195 ( $7^{\text {th }}$ Cir. 1997), 18-5(d).

Southern Union Company v. United States, _U.S._, 132 S.Ct.2344, 2012 WL 2344465 (U.S. June 21, 2012), 18-5(d).

United States v. Warschak, 631 F.3d 266 (2010) WL 5071766.

Ursery, United States v., 518 U.S. 267 (1996), 1-4(c), 1-5(a)(2), 2-2, 2-4, 2-10, 2-10(b), 14-2.

Various Items of Personal Property, United States v., 282 U.S. (1931).

Voigt, United States v., 89 F.3d 1050 (3d Cir. 1996, 11-3(a), 11-3(c), 18-5(d), 209, 22-2(b), 22-3(b).

\section{NORMAS JURÍDICAS CITADAS}

Código Penal de Chile.

Código Penal de España (1848, 1870, 1944).

D.F.L. N $N^{\circ} 213$ de Aduanas.

Enmienda V (EE.UU.).

Enmienda VI (EE.UU.).

Enmienda VII (EE.UU.).

Ley № 11.564 de 1954 sobre el beneficio habitual de animales vacunos.

Ley $N^{\circ} 18.410$ que crea la Superintendencia de Electricidad y Combustible.

Ley $N^{\circ} 18.892$ de pesca y acuicultura.

Ley $N^{\circ} 19.419$ de 1995 que regula las actividades relacionadas con el tabaco.

Ley $N^{\circ} 19.913$ que crea la unidad de análisis financiero y modifica diversas disposiciones en materia de lavado y blanqueo de activos.

Ley № 20.283 de sobre recuperación del bosque nativo y fomento forestal.

Ley $N^{\circ} 20.920$ establece el marco para la gestión de residuos, la responsabilidad extendida del productor y fomento al reciclaje.

Proyecto de Nuevo Código Penal (2014).

United States Code (USC). 